\title{
HOW TO DOUBLE THE BF VOLUME AND PRODUCTION WITH LIMITED CHANGES TO PLANT INFRASTRUCTURE. A PW EXPERIENCE*
}

\author{
Sunil Katharia ${ }^{1}$ \\ Nagendra Kumar ${ }^{2}$ \\ Mirko Bassetti ${ }^{3}$ \\ Marco Perato 4 \\ Jaipal Yadav 5 \\ Antonio Maestri ${ }^{6}$ \\ Roberto Cambria ${ }^{7}$
}

\begin{abstract}
In February 2016, the upgraded Blast Furnace 1 of JSW Steel Limited (JSW) at its Vijayanagar Steel Plant was blown in after a 6 months shutdown in which the whole furnace was rebuilt on the existing foundation and within the existing tower structure. Despite several plant constraints it was possible to increase the furnace inner volume by $85 \%$ - reaching $2307 \mathrm{~m}^{3}$ from existing $1250 \mathrm{~m}^{3}$. The upgradation project covered the stockhouse and its dedusting system, top charging system, furnace profile, furnace cooling system, casthouse and its dedusting system, slag granulation plant, pulverized coal injection plant, hot blast system and gas cleaning plant - with major interventions in order to cope up with the changed operating conditions. The total scope of the project was split by JSW into several packages, all based on design data provided by Paul Wurth. JSW was responsible for coordinating the local subcontractors along with Paul Wurth which has been appointed as main technology supplier in charge of complete basic and selected detail engineering in the key areas and of the supply of core equipment such as the Bell-less Top $®$, copper staves, GCP key items and TMT casthouse machines. The main design concept and the key points of the project such as optimization of project ROI, advanced erection concepts as well as a summary of the operating results are presented confirming JSW "BF1" upgradation as one latest examples of the current state of the art in the revamping projects.
\end{abstract}

Keywords: Blast furnace; Blast furnace upgradation; Blast furnace revamping; Blast furnace erection methodology.

1 Mechanical Engineer, Head of BF Project, Projects, JSW Steel Ltd Vijayanagar works, Toranagallu, Karnataka, India.

2 Mechanical Engineer, Project Manager, Projects, JSW Steel Ltd Vijayanagar works, Toranagallu, Karnataka, India.

Mechanical Engineer, Project Manager, BU Iron, Paul Wurth Italia, Genova, Italy.

4 Mechanical Engineer, Head of BF Process, BU Iron, Paul Wurth Italia, Genova, Italy.

5 Mechanical Engineer, Project Manager, BU Iron, Paul Wurth India Pvt. Ltd., Gurgaon, Haryana, India.

6 Site Manager, Global Site Activities, Paul Wurth Italia, Genova, Italy.

7 Site Supervisor, Global Site, Paul Wurth Italia, Genova, Italy. 


\section{INTRODUCTION}

As a part of JSW Steel Limited, Vijayanagar expansion project the existing iron making capacity was required to be increased without any addition of new blast furnaces. JSW therefore decided to increase the capacity of its Blast Furnace 1, the first blast furnace built in Vijayanagar works and commissioned in 2004, from the existing capacity of $0.875 \mathrm{MTPA}$ to an increased production target of 1.87 MTPA.

Blast Furnace 1 in fact was approaching its first 10 years of campaign during which refractory lining in stack got worn out and cast iron staves were exposed to the burden and gas causing a premature wear of the staves and water leakages into the furnace. Additionally existing hot stoves showed hot spots in the hot blast branch and dome area. In view of the above, JSW decided to reline the furnace and this was seen as an opportunity to infuse state of the art technology and further expand its capacity. Therefore, several configurations were examined and discussed. Finally the configuration, which provided the biggest volume, within the existing tower structure and using the existing furnace foundation, was selected.

\section{PROJECT OVERVIEW}

A joint effort to optimize project CAPEX was executed by PW and JSW with the aim to maximize retention and reuse of the existing systems and items. A critical study of all the existing facilities was carried out with the aim of judiciously balancing new and reused equipment on the basis of the effective need for their replacement. After this study, it became clear that meeting the project targets did not mean an equally heavy intervention in all the areas of the plant: some units could benefit from a generously sized original design and therefore could be retained with improvements/modifications. This has been the case of Stockhouse, BF foundation and tower structure, Top gas piping, Scrubber and Demister shell, Water treatment, Slag Granulation. All the other auxiliary units of the Blast Furnace plant, instead, have been heavily modified or substituted in order to align their features with the new operational needs of the enlarged Blast Furnace.

In order to achieve the basic goal of Blast Furnace No.1 upgradation project such as plant capacity enhancement a combination of the following factors was considered:

- Adoption of state of the art technology improving plant productivity and reliability

- Increase of Furnace volume to the maximum extent within the existing tower In terms of plant performance the comparison between the existing furnace and the new furnace can be shortly listed as follows:

- Average daily production increase from $2500 \mathrm{HMt} / \mathrm{d}$ to $5250 \mathrm{HMt} / \mathrm{d}(+110 \%)$ for an yearly BF throughput of 1.87 MTPA considering $355 \mathrm{~d} / \mathrm{y}$ of plant availability

- $\mathrm{PCl}$ average injection rate increase from $100 \mathrm{~kg} / \mathrm{HMt}$ to $150 \mathrm{~kg} / \mathrm{HMt}$

- Hot Blast temperature increase from $1050^{\circ} \mathrm{C}$ to $1200^{\circ} \mathrm{C}$

- Higher utilization factor (355 d/y)

- Lower environmental pollution load

The main new Blast Furnace parameters and key data vs. the old ones are shown in Table 1. 
Table 1. Major design figures of Blast Furnace No.1 before and after upgradation

\begin{tabular}{lcc}
\hline & $\begin{array}{c}\text { Existing } \\
\mathbf{2 0 0 4 - 2 0 1 6}\end{array}$ & $\begin{array}{c}\text { New } \\
\text { Since 2016 }\end{array}$ \\
\hline Hearth Diameters & $8.0 \mathrm{~m}$ & $10.4 \mathrm{~m}$ \\
\hline Working Volume & $1105 \mathrm{~m}^{3}$ & $2000 \mathrm{~m}^{3}$ \\
\hline Inner Volume & $1250 \mathrm{~m}^{3}$ & $2307 \mathrm{~m}^{3}$ \\
\hline Average Production & $2500 \mathrm{t} / \mathrm{d}$ & $5250 \mathrm{t} / \mathrm{d}$ \\
\hline Number of Tuyeres & 18 & 28 \\
\hline Hot Blast Parameters & $110 \mathrm{kNm} / \mathrm{h} @ 1050{ }^{\circ} \mathrm{C}$ & $230 \mathrm{kNm} / \mathrm{h} @ 1200^{\circ} \mathrm{C}$ \\
\hline Top Gas Parameters & $150 \mathrm{kNm} / \mathrm{h} @ 1.2 \mathrm{bar} \mathrm{g}$ & $370 \mathrm{kNm} / \mathrm{h} @ 1.5 \mathrm{bar} \mathrm{g}$ \\
\hline Ave. PCI rate & $100 \mathrm{~kg} / \mathrm{tHM}(17.5 \mathrm{t} / \mathrm{h})$ & $150 \mathrm{~kg} / \mathrm{tHM}(50 \mathrm{t} / \mathrm{h})$ \\
\hline Oxygen Enrichment & $4 \% \mathrm{max}$ & $8 \% \mathrm{max}$ \\
\hline
\end{tabular}

The project scope was split in several packages with a clear responsibility matrix; $\mathrm{JSW}$, acting as the project leader, ensured the necessary and timely exchange of information, the progress monitoring and the proactive expediting.

Paul Wurth, appointed as main technology provider, was responsible for the main package covering:

- Basic engineering and Detail engineering for critical items

- Concept engineering for critical erection activities

- Supply of critical items such as copper staves, new BLT, Key items of GCP including a brand new Axial Cyclone, Key items of $\mathrm{PCl}$, new $\mathrm{CH}$ machines and relevant hydraulic system, Tuyere Stocks

- Supervision and testing of critical items supplied by JSW

- Supervision of erection, commissioning and performance tests JSW Steel undertook the responsibility of coordinating the balance activities

\section{PROJECT ACTIVITIES}

\subsection{Stockhouse and charging system}

After a complete analysis of the charging system it was decided to retain the existing Stockhouse building and screening equipment increasing storage capacity by two additional modules of bins. The modification of fine system and weighing hoppers was performed. A completely new dedusting system to reduce dust emission and improve working environment was installed.

Major intervention was focused on main charging conveyor system as follow:

- Installation of new surge hoppers for coke and ferrous materials

- Increase of belt capacity to $2150 \mathrm{t} / \mathrm{h}$ by increasing its speed $(3.0 \mathrm{~m} / \mathrm{s})$ and relocating the drive units at ground

- Strengthening and Modification of existing galleries and trestles increasing their height (up to +7 meters) to match the increased BF top charging unit level, see Figure 1. 


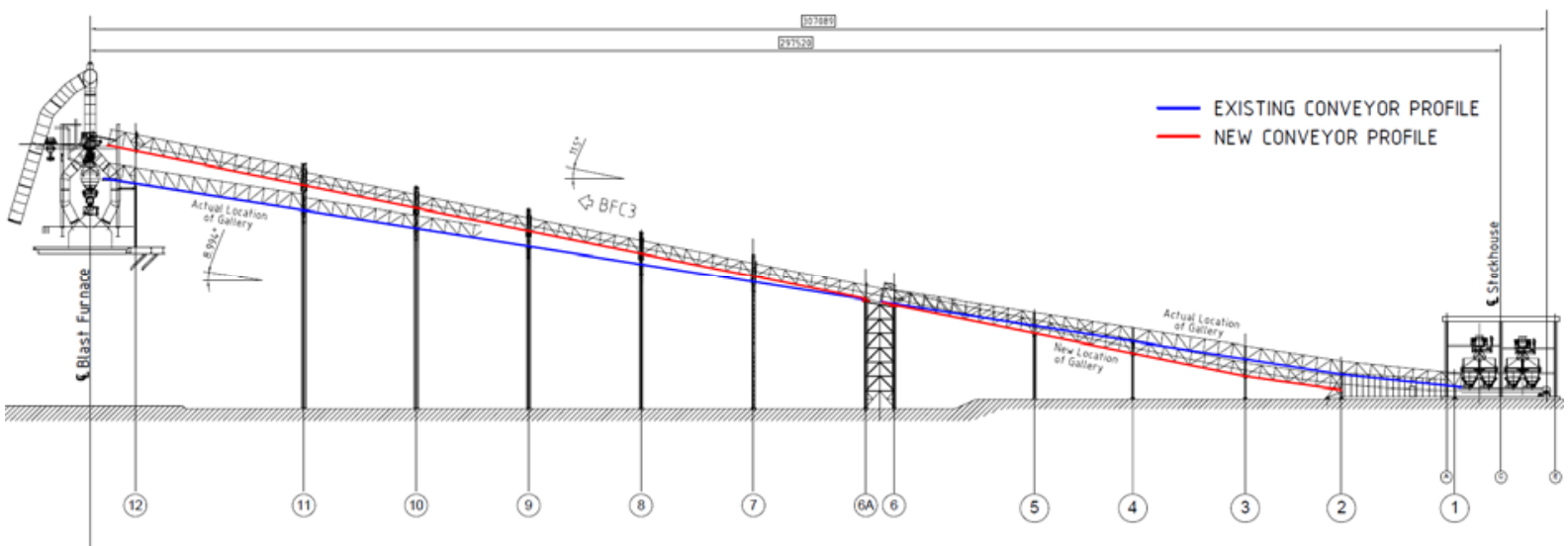

Figure 1. Main Charging conveyor before and after upgradation.

\subsection{BF proper}

To optimize the project ROI, the solution considering maximization of furnace volume within the existing tower recovering the existing foundation was selected. With a detailed engineering approach, it was possible to increase the furnace volume by approx. $85 \%$. The BF foundation could be reused (with strengthening) thanks to the adoption a BF shell socket design allowing to erect new anchor bolts and base ring on existing foundation base area embedding the original foundation above ground, see Figure 2.

The new BF profile (see Figure 2) and the philosophy of water cooling system required the replacement of whole BF shell and augmentation of water circulating amount (approx. $4200 \mathrm{~m}^{3} / \mathrm{h}$ ) with the provision of 4 separate cooling circuits and a new pump-house. Thanks to the adoption of thin wall stave cooling in place of previously adopted cast iron staves with refractory, it has been possible to accommodate a new larger BF volume with a relatively limited increase of shell dimensions. Local modification and strengthening of existing tower structure with addition of external floors to support a new enlarged bustle pipe and redesign of inner platforms to allow the expansion of furnace volume to the maximum extent was considered.

The furnace profile was developed considering the reuse of already available copper staves previously ordered by JSW for a different project by designing of tailor-made additional copper staves. Copper staves were installed in 6 rows from bosh to mid stack up to an height of $11.75 \mathrm{~m}$ above tuyere centerline with the rest of furnace wall cooled by cast iron staves. For the first time in India, PW patented copper staves with abrasion resistant hot face were provided.

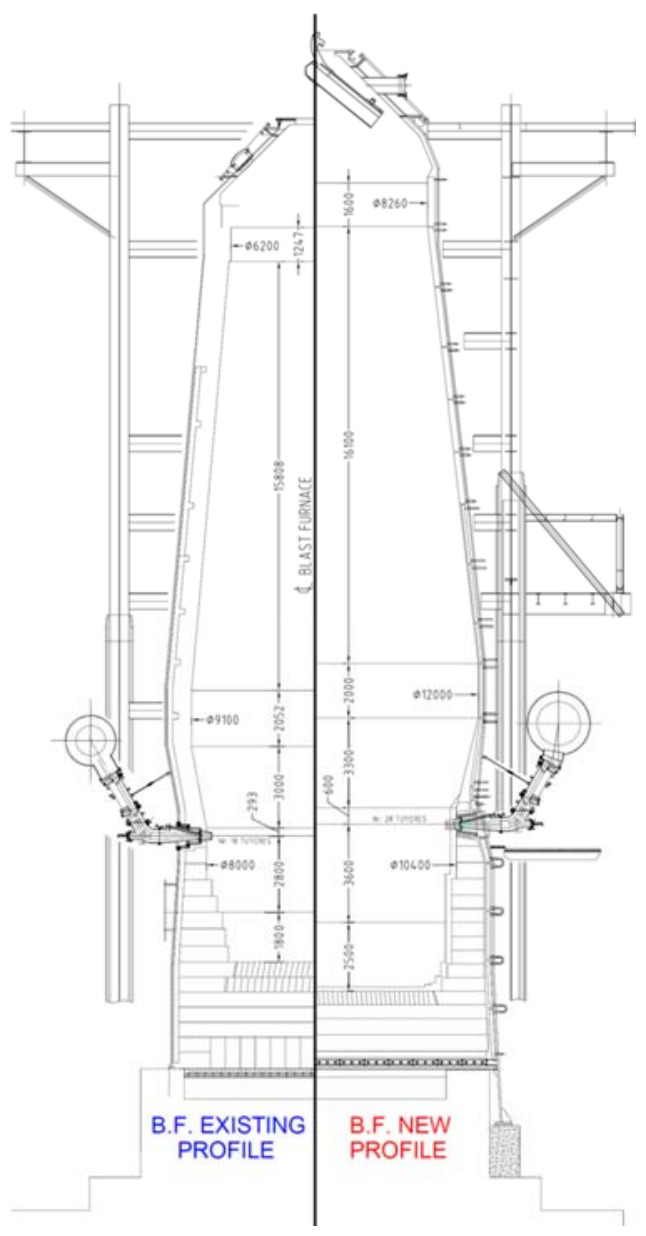

Figure 2: Comparison of BF cross section 
In place of the former PW MINI BLT ${ }^{\circledR}$ with single material hopper a new PW MIDI BLT® with parallel hoppers of $26 \mathrm{~m}^{3}$ each was installed inside the existing top gas piping. Accordingly, main charging conveyor discharge head elevation has been lifted by approx. $7 \mathrm{~m}$. An overall update of the top equipment was implemented with the installation of a complete new set of valves with relevant hydraulic and greasing system.

The $\mathrm{Cl}$ staves cooled hearth design has been improved by adoption of SuperMicropore carbon blocks with monolithic taphole blocks and sump depth rise from 1.8 to $2.5 \mathrm{~m}$ increasing expected campaign life. In particular the adoption of the unique taphole gas sealing system, developed by PW, targets an higher reliability of the taphole area given the zeroing of gas leakages that this design implies.

\subsection{Casthouse}

In this area, it was possible to retain existing casthouse building, overhead cranes, most of floor structures, tilting runners as well as part of existing slag runners. Modifications have been made to cope up with the increase of casting rate and enlarged furnace profile by new main iron through with forced air cooling and new runners connections.

Casthouse operation and furnace availability was drastically improved by the substitution of the existing $\mathrm{CH}$ machines with new fully hydraulically operated ones of TMT design with relevant hydraulic system.

The existing slag granulation plant, consisting of PW granulation tanks \& stacks and open air filter beds, has been modified to handle the increased amount of slag by the addition of a new filtering bed aside the existing one with a new crane for slag evacuation. Existing granulation pumps were reused increasing the granulation water flow by changing their pulleys to meet new slag peak flowrate. The dedusting plant has been completely renewed installing a new filtering unit, ducting and hoods to allow efficient fume extraction.

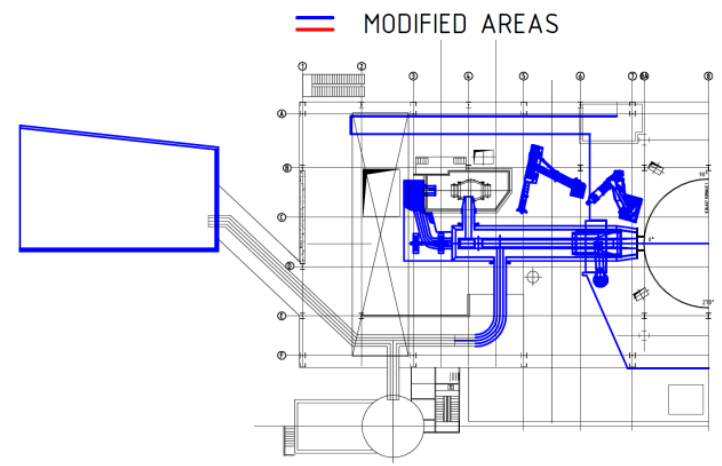

NEW CASTHOUSE LAYOUT

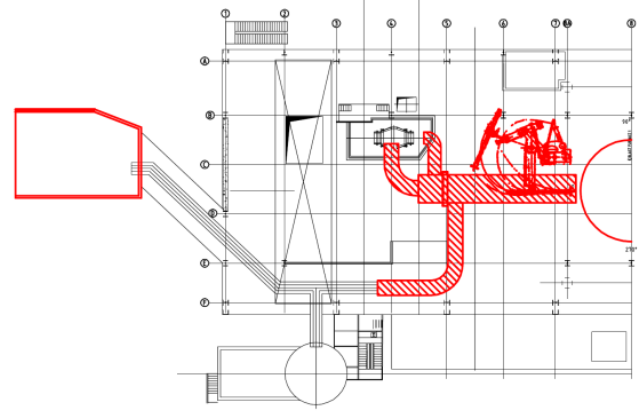

EXISTING CASTHOUSE LAYOUT

Figure 2: Comparison of $\mathrm{CH}$ layout

\subsection{Gas cleaning Plant}

The existing Dust catcher has been replaced by a new PW Axial Cyclone with improved dust separation efficiency designed to cope the new top gas flowrates. In the wet scrubber area, it was possible to retain the existing scrubber and demister vessels and structures. New connection pipe from axial cyclone to wet GCP, new internal GCP ducting and new PW Venturi and Saturation throats have been applied with upgraded design. New demister internals were designed to improve droplets separation efficiency and new septum valve and TRT provision were provided. 


\subsection{PCl system}

The former $\mathrm{PCl}$ system with capacity of $17.5 \mathrm{t} / \mathrm{h}$ was upgraded to deliver up to $50 \mathrm{t} / \mathrm{h}$ of coal allowing a theoretical maximum injection rate to the new BF of approx. $230 \mathrm{~kg} / \mathrm{t}$ at average production.

In order to retain at the maximum extent the existing system, a PW tailor-made solution foreseeing the introduction of a new intermediate hopper $\left(31 \mathrm{~m}^{3}\right)$ in-between the existing injection hoppers and a new static distributor located inside $\mathrm{CH}$ building was developed. By this approach a complete recover of the existing fine coal silo, $\mathrm{PCl}$ structures and existing injection hoppers were achieved. Newly designed fluidizing chambers connected to the bottom of existing injection hoppers, new scalping devices, coal GRITZKO ${ }^{\circledR}$ flow control valve, conveying lines and lances were provided.

\subsection{Advanced Dismantling and Erection Concepts}

Several measures and erection methodologies to minimize the overall duration of the shutdown time were conceived by PW. In particular, some points were addressed adopting techniques experienced for the first time such as the pre-assembly of a complete new upper tower along with the new BLT and their single block erection in a single lift. See Figure 3.
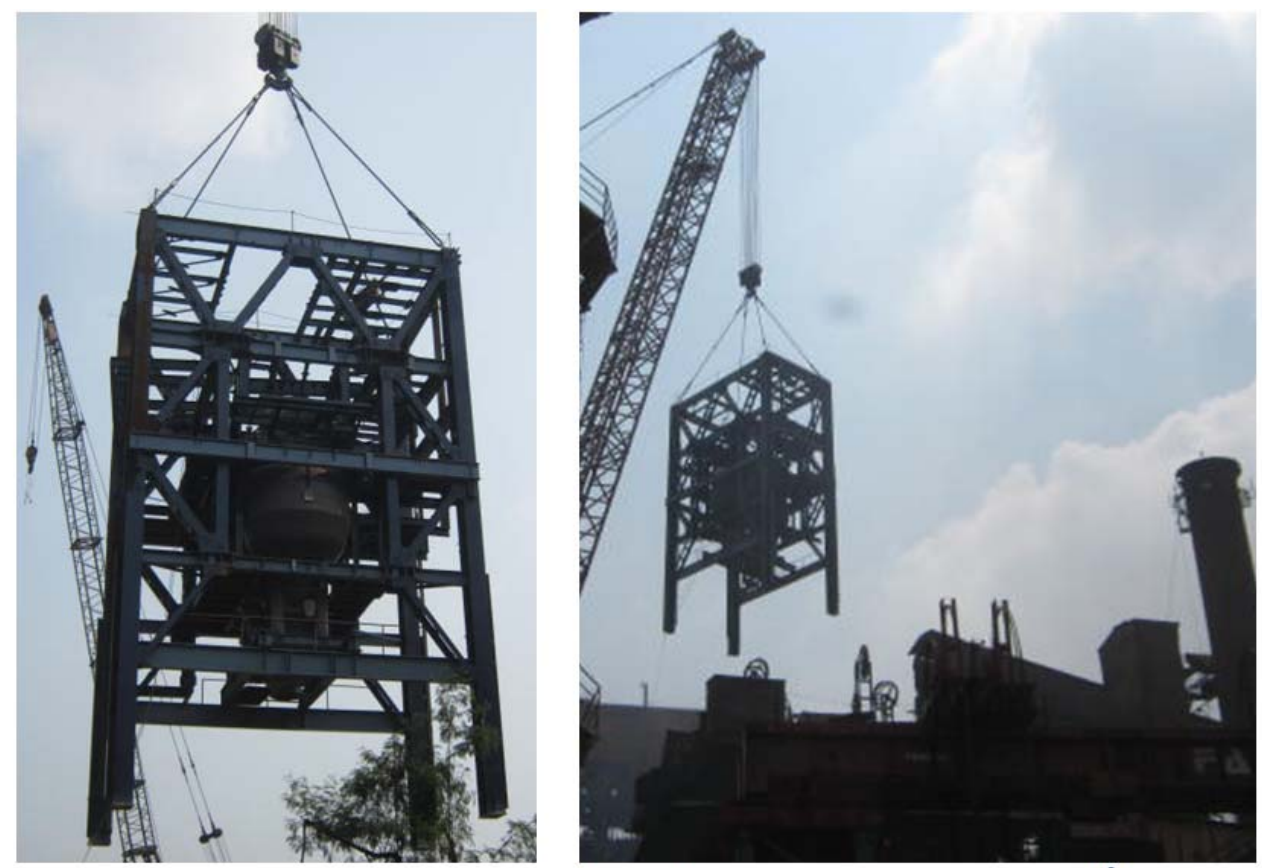

Lifting weight:

- Structure 325t

- BLT Equipments 110t

Total weight: $435 \mathrm{t}$

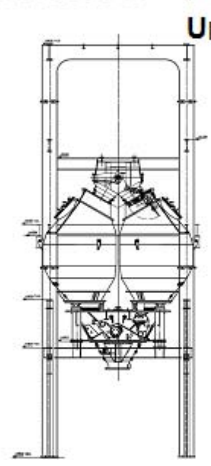

Upper Tower
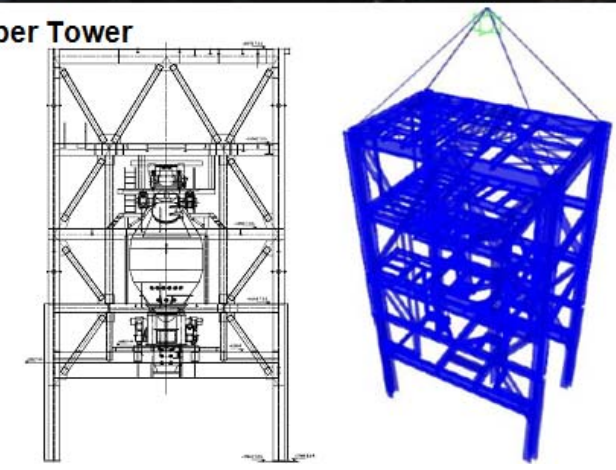

Figure 3. One shot installation new BLT/Upper Tower 
Substantial quantity of work was completed, while the old furnace was still in operation. The most significant activities carried out before BF shutdown have been:

- Strengthening and partial modification of existing tower structure, furnace foundation, and main charging conveyor structures

- Construction on new BF cooling pump house with new cooling towers

- Extension of the PCI building to accommodate the intermediate hopper

- Construction and preassembly of new BF upper tower

- Fabrication of new furnace and axial cyclone shells with preassembly in big blocks along with cooling elements, platforms, etc.

Existing and new Furnace shells were dismantled (see Figure 4) /erected (see Figure 5 ) by means of large block shifting method respectively in 4 and 5 pieces with a maximum single rings weight of about 400 tons.

The entire shell weight from tuyere axis up to top cone has been supported from top platform and lowered/lifted by four strand jacks with a capacity of 450tons each. To this purpose, the entire tower structure during lifting condition has been strengthened according to PW engineering to sustain an overall load of approx. 1600tons.

Strand jacks, SMPT cars and Skid tracks system passing above cast house floor were adopted for shell rings handlings, see Figures 4-5.
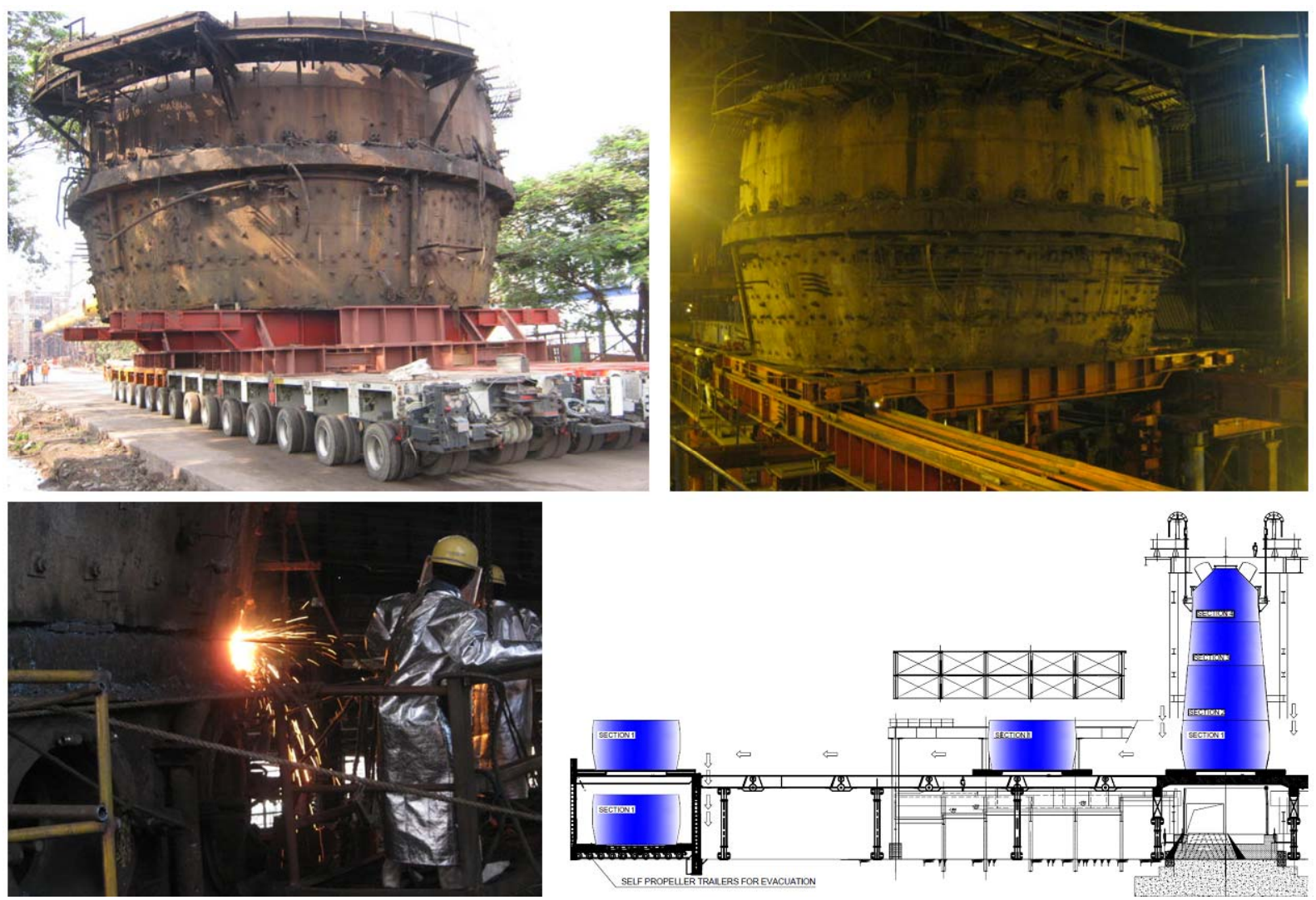

Figure 4. Removal of old shell with large blocks method 

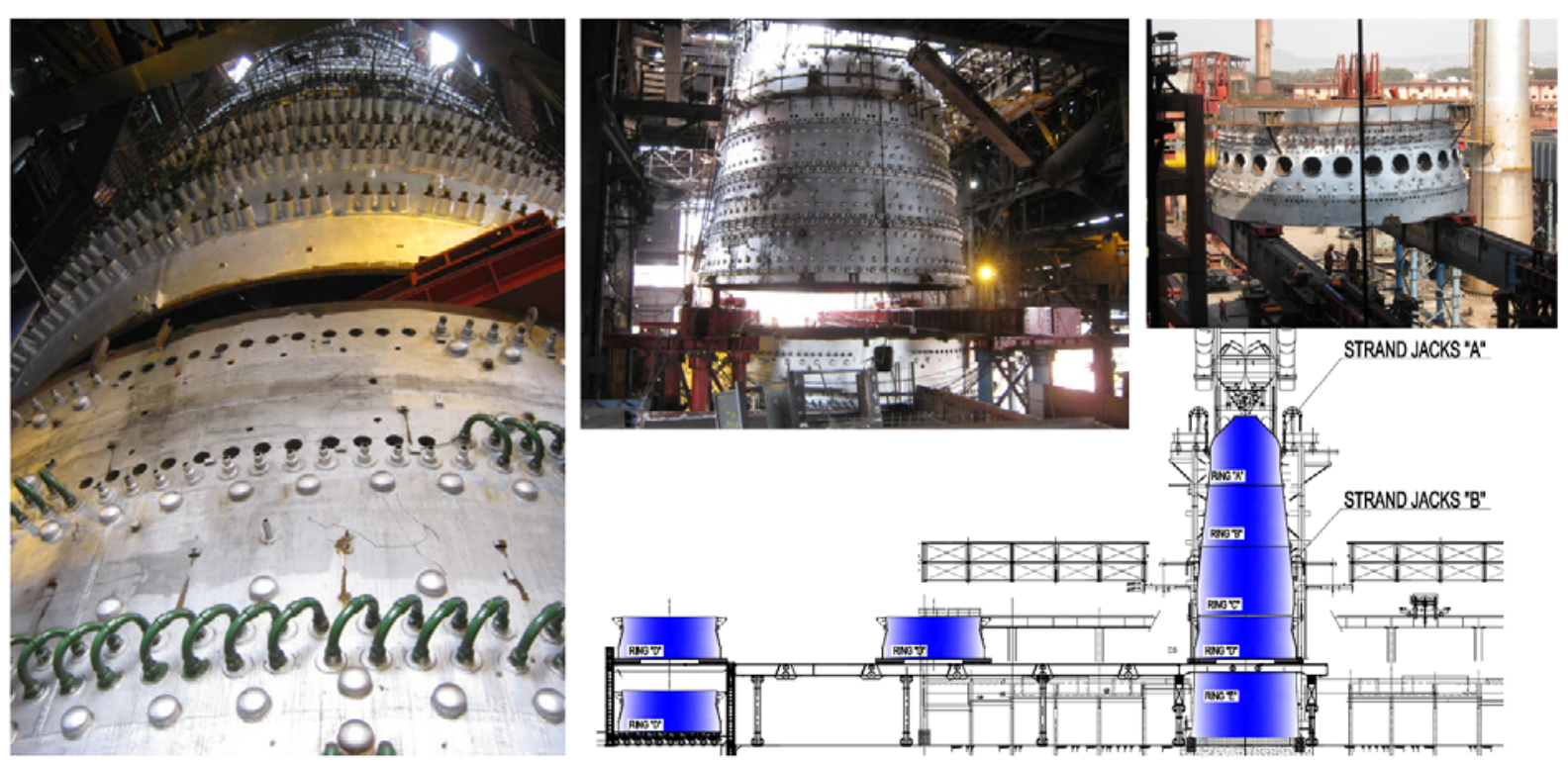

Figure 5. Installation new BF shell with large blocks method

Another major activity was the repositioning of the main charging conveyor which was executed without any lowering to the ground of the existing galleries and trestles. Existing conveyor structures were modified beforehand and extended in place according to the new conveyor profile, as shown in Figure 1, lifted up to $7 \mathrm{~m}$ from their original position, see Figure 6 , and fixed into their final position at a working height up to approx. $56 \mathrm{~m}$.
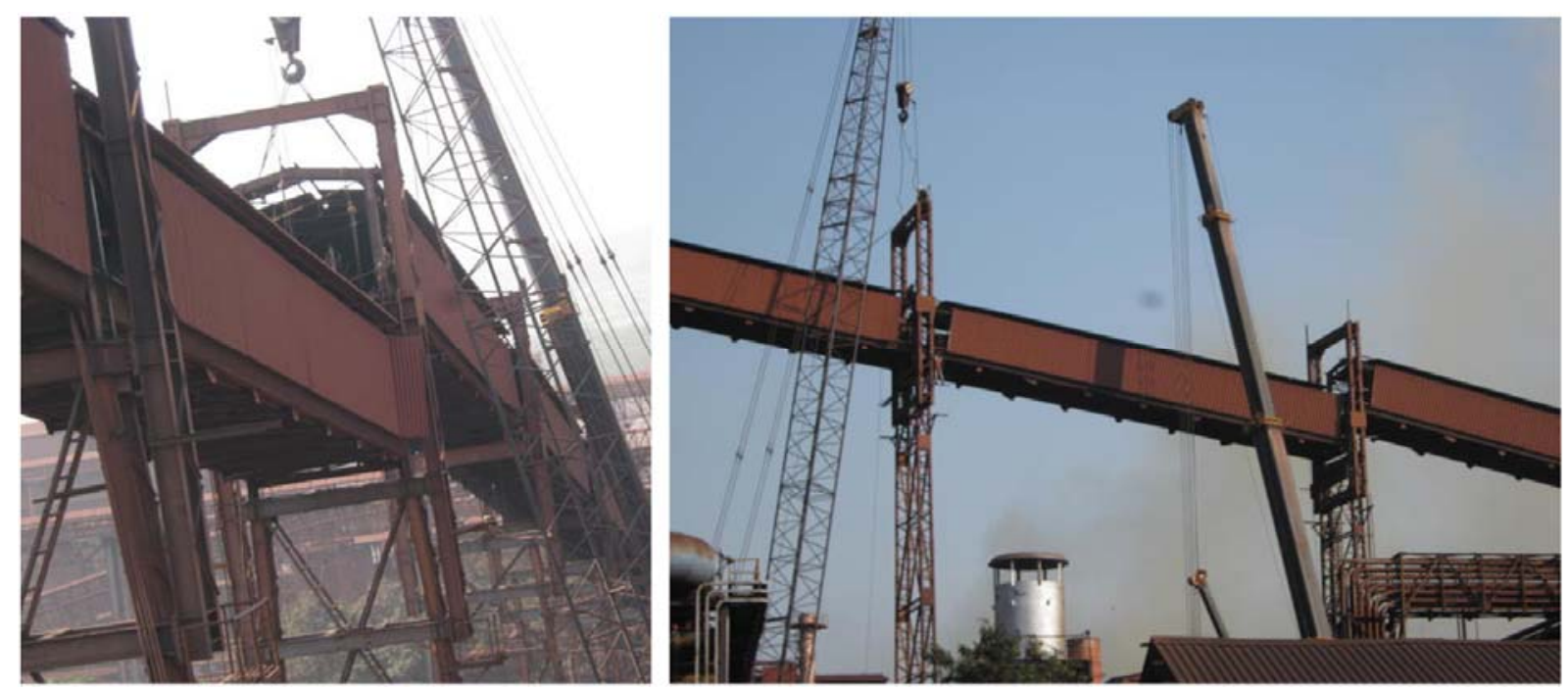

Figure 6. Lifting of main charging conveyor

PW involvement started with the concept engineering of all key erection activities including erection sequence drawings, main lifts sketches, shutdown schedule, supervision of erection and commissioning phases. Examples are given in Figure 7. 


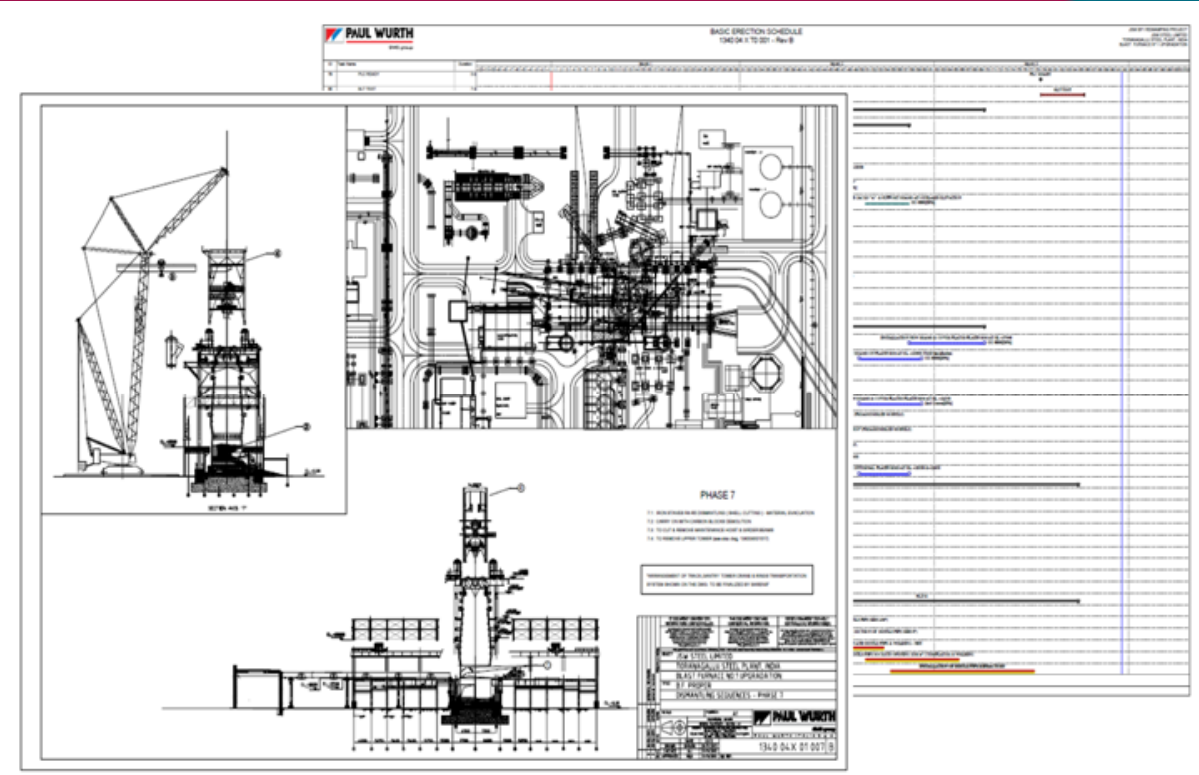

Figure 7. Example of Shutdown schedule and erection drawings developed by PW.

\subsection{BF commissioning and Blowin and BF performance}

BF commissioning and blow-in were rapidly completed. A smooth cast of first Hot Metal was ensured by carefully designing the BF first filling and blast ramp-up, starting from the hearth filled with wood and subsequently by a smooth increase of the ore/coke ratio from 0 to 2.0 with the last charges. A summary of the main results of operation of upgraded Blast Furnace No.1 during its first month of operation are given in Figure 8.

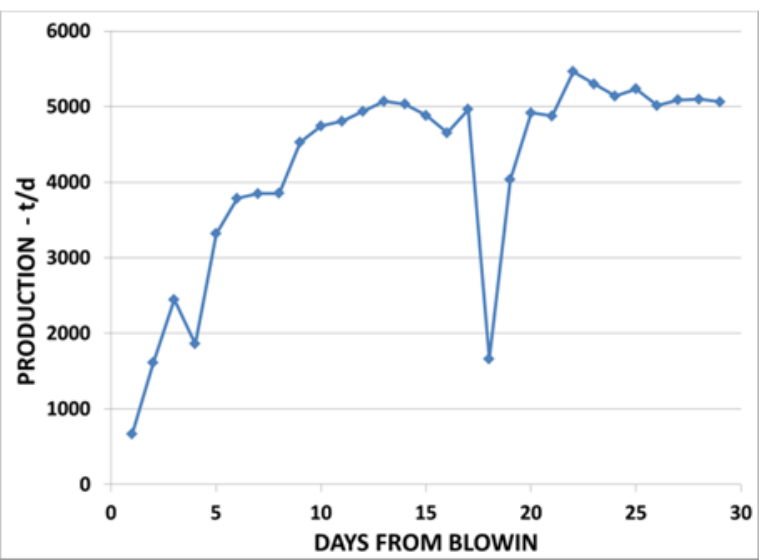

Figure 8. Blast furnace Production from Blowin

It is worth to highlight the fast furnace ramp-up and the production level exceeding the nominal production on constant basis especially considering the average slag rate of more than $420 \mathrm{~kg} / \mathrm{t}$ resulting from the use of local low grades iron ores.

\section{CONCLUSIONS}

This paper has shortly described the main features of the JSW Blast Furnace 1 upgradation project. The furnace is currently operating successfully with production levels exceeding expected performance. JSW Blast Furnace 1 project experience proves that a good cooperation between plant owner (JSW), main technological provider (Paul Wurth) and all the agencies involved in the project allowed to achieve 
remarkable results such as an increase of furnace volume by approx. $85 \%$ within the existing tower, an increase of plant capacity by approx. $110 \%$ and an optimized project CAPEX thanks to the careful selection and balance of new and revamped units. Challenging erection concepts and methodologies were also an important part of the revamping project, having set new standards in BF construction technologies applied in India. 